\title{
Fractional flow in radial flow systems: a study for peripheral waterflood
}

\author{
Kegang Ling ${ }^{1}$
}

Received: 28 December 2014/ Accepted: 2 August 2015/Published online: 16 November 2015

(C) The Author(s) 2015. This article is published with open access at Springerlink.com

\begin{abstract}
The Buckley-Leverett displacement mechanism has been used to predict the performance of waterflood. With Buckley-Leverett method, oil recovery from waterflood is calculated and required water injection volume to achieve that oil recovery is estimated. This method does provide a very useful tool in waterflood design. Our experience in oil industry and a thorough literature review indicates that BuckleyLeverett method was used to analyze waterflood project directly without any adjustment based on the real reservoir and production situations. By doing so, errors are introduced into the analysis. Buckley-Leverett method assumed that displacement occurs in a linear system. This is true for some waterflood scenarios while for others it is not. For some waterflood scenarios, a radial system is more appropriate than a linear system. In this study, we investigated the fractional flow in a radial system and derived the solutions to predict the performance of water displacing oil in radial system. With this radial displacement model, design and prediction of waterflood can be achieved by Buckley-Leverett method and our model, whichever fits the waterflood pattern. Considering the fact that many waterflood scenarios follow radial displacement, our model is an important supplement to BuckleyLeverett method.
\end{abstract}

Keywords Waterflooding - Radial flow system · Fractional flow

\section{List of symbols \\ A Flow area}

Kegang Ling

kegangling@yahoo.com

1 University of North Dakota, Grand Forks, ND, USA $c_{\mathrm{w}} \quad$ Water compressibility

$f_{\mathrm{w}} \quad$ Water fraction

$h \quad$ Reservoir thickness

$k \quad$ Reservoir permeability

$k_{\text {ro }} \quad$ Relative permeability to oil

$k_{\text {rw }}$ Relative permeability to water

$P_{\mathrm{c}} \quad$ Capillary pressure

$P_{\mathrm{d}} \quad$ Threshold pressure in capillary pressure curve

$p \quad$ Pressure

$p_{\mathrm{o}} \quad$ Oil pressure

$p_{\mathrm{w}} \quad$ Water pressure

$p_{\mathrm{wf}} \quad$ Flowing bottomhole pressure

$q_{\mathrm{o}} \quad$ Oil rate

$q_{\mathrm{t}} \quad$ Total liquid rate

$q_{\mathrm{w}} \quad$ Water rate

$r \quad$ Radius from center of wellbore

$r_{\mathrm{D}} \quad$ Dimensionless radius

$r_{\mathrm{e}} \quad$ Reservoir outer boundary radius

$r_{\mathrm{f}} \quad$ Displacement front position in radial system

$r_{S_{\mathrm{w}}} \quad$ Position of any water saturation in radial system

$r_{\mathrm{w}} \quad$ Wellbore radius

$\Delta r \quad$ Radius incremental

$S_{\mathrm{w}} \quad$ Water saturation

$S_{\text {wi }} \quad$ Irreducible water saturation

$T$ Temperature

$\Delta t \quad$ Time period

$t \quad$ Time

$V \quad$ Volume

$x_{\mathrm{f}} \quad$ Displacement front position in linear system

$\oint$ Porosity

$\rho_{\mathrm{w}} \quad$ Water density

$\mu_{\mathrm{o}} \quad$ Oil viscosity

$\mu_{\mathrm{w}} \quad$ Water viscosity

$\lambda$ Rock property parameter related to the distribution of pore sizes 


\section{Introduction}

When reservoir engineers analyze the waterflood performance, they resort to the conventional frontal advance theory of Buckley and Leverett (1942). With BuckleyLeverett method, oil recovery from waterflood is calculated and required water injection volume to achieve that oil recovery is estimated. This method does provide a very useful tool in waterflood design. Welge (1952) proposed a tangent construction method to estimate the water saturation, water fraction at the water front and oil recovery factor. Several other investigators studied the multilayer reservoir waterflood performance. Stiles (1949) investigated the multilayer reservoir displacement by assuming the displacement velocity in a layer to be proportional to its absolute permeability. Dykstra and Parsons (1950) developed their famous multi-permeability model for noncommunicating layers without crossflow. Hearn (1971) derived expressions for communicating stratified reservoirs using the pseudo-relative permeability functions. El-Khatib (1999) advanced the closed form analytical solution for communicating stratified systems with log-normal permeability distributions. To the best of our knowledge, none of the study considered water displacing oil in a radial reservoir system.

It should be noted that Buckley-Leverett method and all the aforementioned studies assumed that displacement occurs in a linear system. This is true for some waterflood scenarios, while for others it is not. Our experience in oil industry and a thorough literature review indicates that petroleum engineers used Buckley-Leverett method to analyze the waterflood project directly without any adjustment based on the real reservoir and production situations such as production-injection patterns. By doing so, a lot of errors are introduced into the analysis. For some waterflood scenarios, a radial system is more appropriate than a linear system. Therefore, a radial displacement model is a necessary supplement to Buckley-Leverett linear displacement model. With both displacement models, design and prediction of waterflood can be achieved by selecting the appropriate model that fits the waterflood pattern. Considering the fact that many waterflood scenarios follow radial displacement, our model is very useful in field application.

\section{Derivation of fractional flow in a radial reservoir system}

Figure 1 shows a circular reservoir with a well located in the center. For oil reservoir with strong peripheral water drive or surrounded by peripheral injectors, Fig. 1 can represent the displace procedure well. The fractional flow can be viewed as water displacing oil into the central well. Figure 2 illustrates the flow line and pressure distribution in the reservoir. To make the analysis simple, the following assumptions are made:

1. A circular reservoir with constant height

2. Reservoir is homogenous in all rock properties

3. The dip angle of the formation is zero

4. Oil and water two-phase flow in reservoir, no gas presents in the reservoir

5. Compressibilities of oil and water are negligible

6. The variation in oil and water densities can be neglected

7. Constant reservoir temperature is applied

8. All rock properties do not change as pressure changes

9. Constant oil and water viscosities during the displacement

Starting from Darcy's equation, we have oil and water flow rates to be calculated as:

$q_{\mathrm{o}}=\frac{k k_{\mathrm{ro}}}{\mu_{\mathrm{o}}} \frac{\partial\left(A p_{\mathrm{o}}\right)}{\partial r}$

$q_{\mathrm{w}}=\frac{k k_{\mathrm{rw}}}{\mu_{\mathrm{w}}} \frac{\partial\left(A p_{\mathrm{w}}\right)}{\partial r}$

where $A$ is the flow area, $k$ is the reservoir permeability, $k_{\mathrm{ro}}$ is the relative permeability to oil, $k_{\mathrm{rw}}$ is the relative permeability to water, $p_{\mathrm{o}}$ is the oil pressure, $p_{\mathrm{w}}$ is the water pressure, $q_{\mathrm{o}}$ is the oil rate, $q_{\mathrm{w}}$ is the water rate, $r$ is the radius from wellbore, $\mu_{\mathrm{o}}$ is the oil viscosity, and $\mu_{\mathrm{w}}$ is the water viscosity.

Recalling the concept of capillary pressure we have

$P_{\mathrm{c}}=p_{\mathrm{o}}-p_{\mathrm{w}}$

where $p_{\mathrm{c}}$ is the capillary pressure.

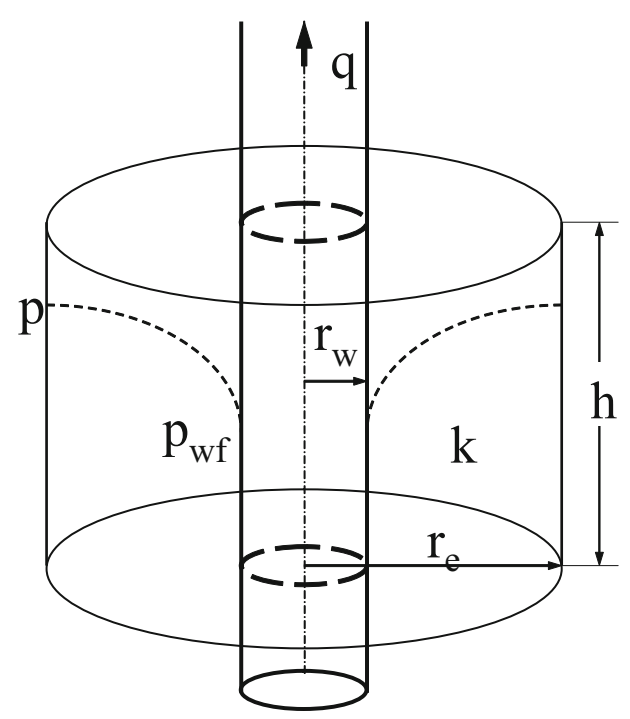

Fig. 1 A circular reservoir with a well located in the center 


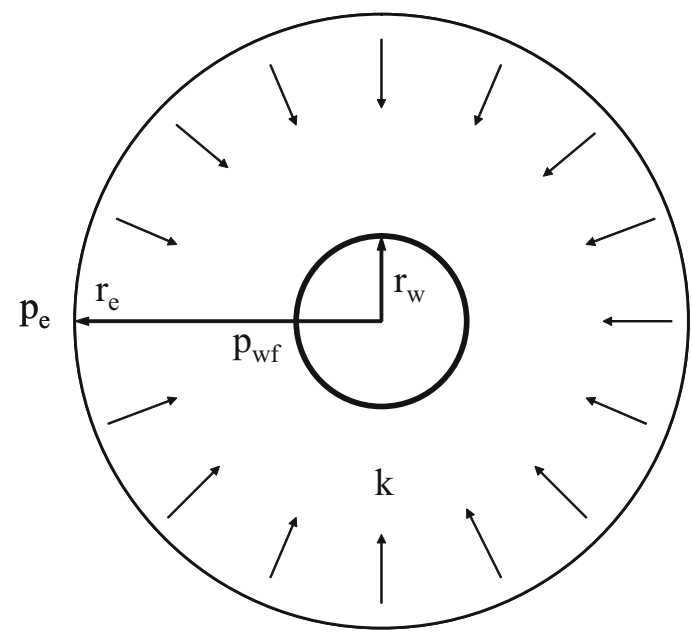

(a)

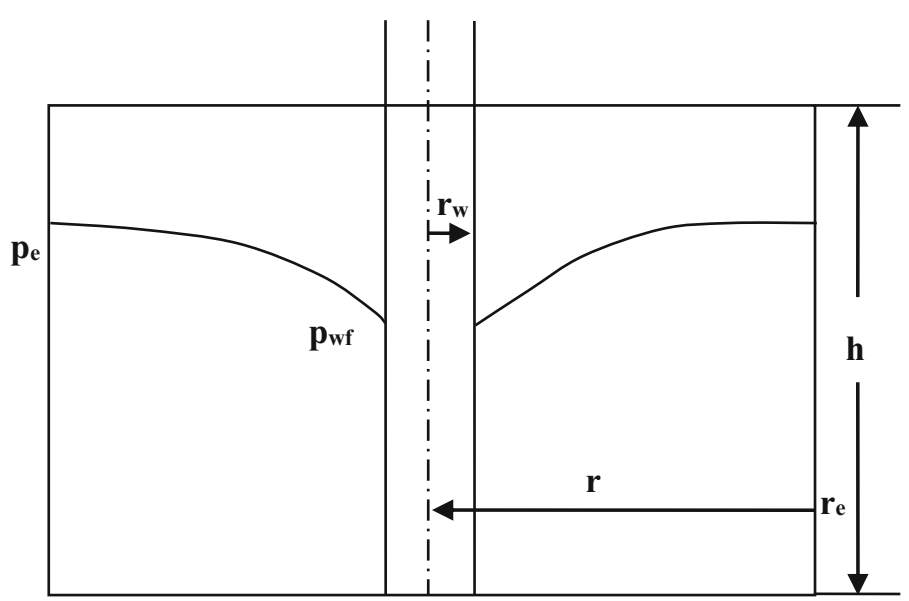

(b)

Fig. 2 Radial flow reservoir system: a plan view, b lateral view

Replacing water pressure by oil and capillary pressure Eq. (2) becomes

$q_{\mathrm{w}}=\frac{k k_{\mathrm{rw}}}{\mu_{\mathrm{w}}} \frac{\partial\left[A\left(p_{\mathrm{o}}-p_{\mathrm{c}}\right)\right]}{\partial r}$.

Expressing in pressure gradient, Eqs. (1) and (4) are changed to

$\frac{\partial\left(A p_{\mathrm{o}}\right)}{\partial r}=\frac{\mu_{\mathrm{o}}}{k k_{\mathrm{ro}}} q_{\mathrm{o}}$

$\frac{\partial\left(A p_{\mathrm{o}}\right)}{\partial r}-\frac{\partial\left(A P_{\mathrm{c}}\right)}{\partial r}=\frac{\mu_{\mathrm{w}}}{k k_{\mathrm{rw}}} q_{\mathrm{w}}$.

Subtracting Eq. (5) from (6), we obtain

$-\frac{\partial\left(A P_{\mathrm{c}}\right)}{\partial r}=\frac{\mu_{\mathrm{w}}}{k k_{\mathrm{rw}}} q_{\mathrm{w}}-\frac{\mu_{\mathrm{o}}}{k k_{\mathrm{ro}}} q_{\mathrm{o}}$

or

$\frac{\partial\left(A P_{\mathrm{c}}\right)}{\partial r}=\frac{1}{k}\left(\frac{\mu_{\mathrm{o}}}{k_{\mathrm{ro}}} q_{\mathrm{o}}-\frac{\mu_{\mathrm{w}}}{k_{\mathrm{rw}}} q_{\mathrm{w}}\right)$.

At this stage, we can introduce the concepts of total liquid rate and fractional flow, which are defined as:

$q_{\mathrm{t}}=q_{\mathrm{o}}+q_{\mathrm{w}}$

$f_{\mathrm{w}}=\frac{q_{\mathrm{w}}}{q_{\mathrm{t}}}$

where $q_{\mathrm{t}}$ is the total liquid rate and $f_{\mathrm{w}}$ is the water fraction.

Substituting Eqs. (8) and (9) into (7) yields

$f_{\mathrm{W}}=\frac{1-\frac{\partial\left(A P_{\mathrm{c}}\right)}{\partial r} \frac{k k_{\mathrm{ro}}}{q_{\mathrm{r}} \mu_{\mathrm{o}}}}{1+\frac{k_{\mathrm{r}} \mu_{\mathrm{w}}}{k_{\mathrm{rw}} \mu_{\mathrm{o}}}}$.

Flow area is defined as:

$A=2 \pi r h$

where $h$ is the reservoir thickness.

Substituting Eq. (11) into (10), we have

$f_{\mathrm{w}}=\frac{1-\frac{2 \pi h k k_{\mathrm{ro}}}{q_{\mathrm{t}} \mu_{\mathrm{o}}}\left(\frac{r \partial P_{\mathrm{c}}}{\partial r}+P_{\mathrm{c}}\right)}{1+\frac{k_{\mathrm{r}} \mu_{\mathrm{w}}}{k_{\mathrm{rw}} \mu_{\mathrm{o}}}}$.

Fig. 3 A control volume in a circular reservoir with a well located in the center
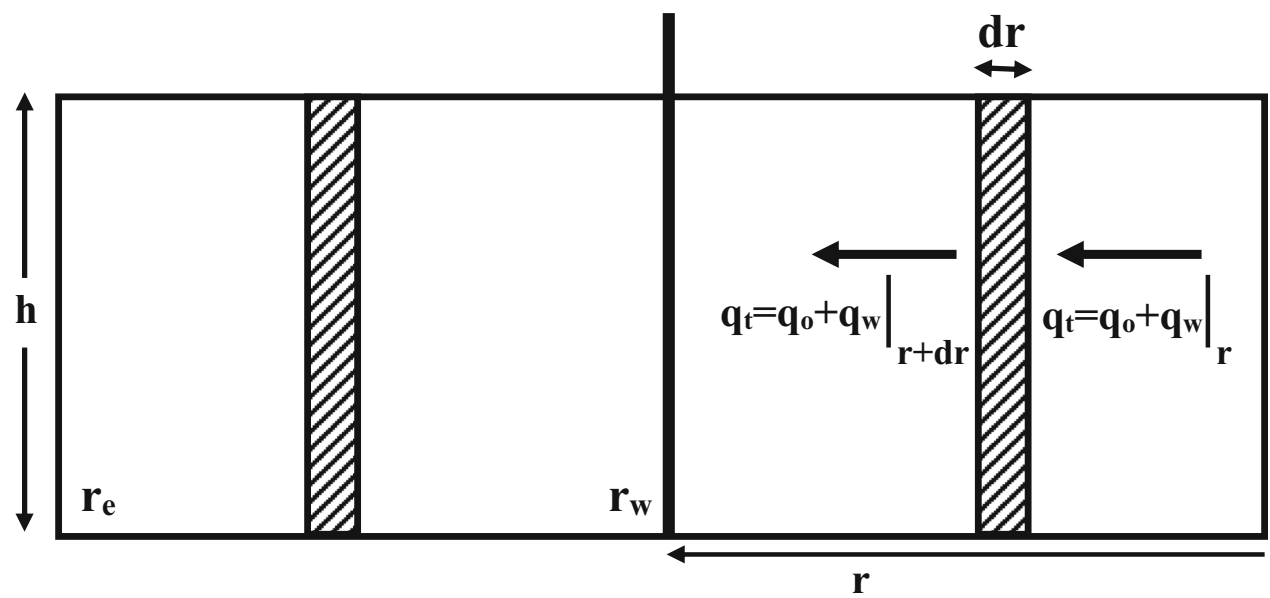
Fig. 4 The plot of water saturation versus dimensionless radius based on Eq. (31)
$\mathbf{S}_{w}$ vs. Dimensionless Radius

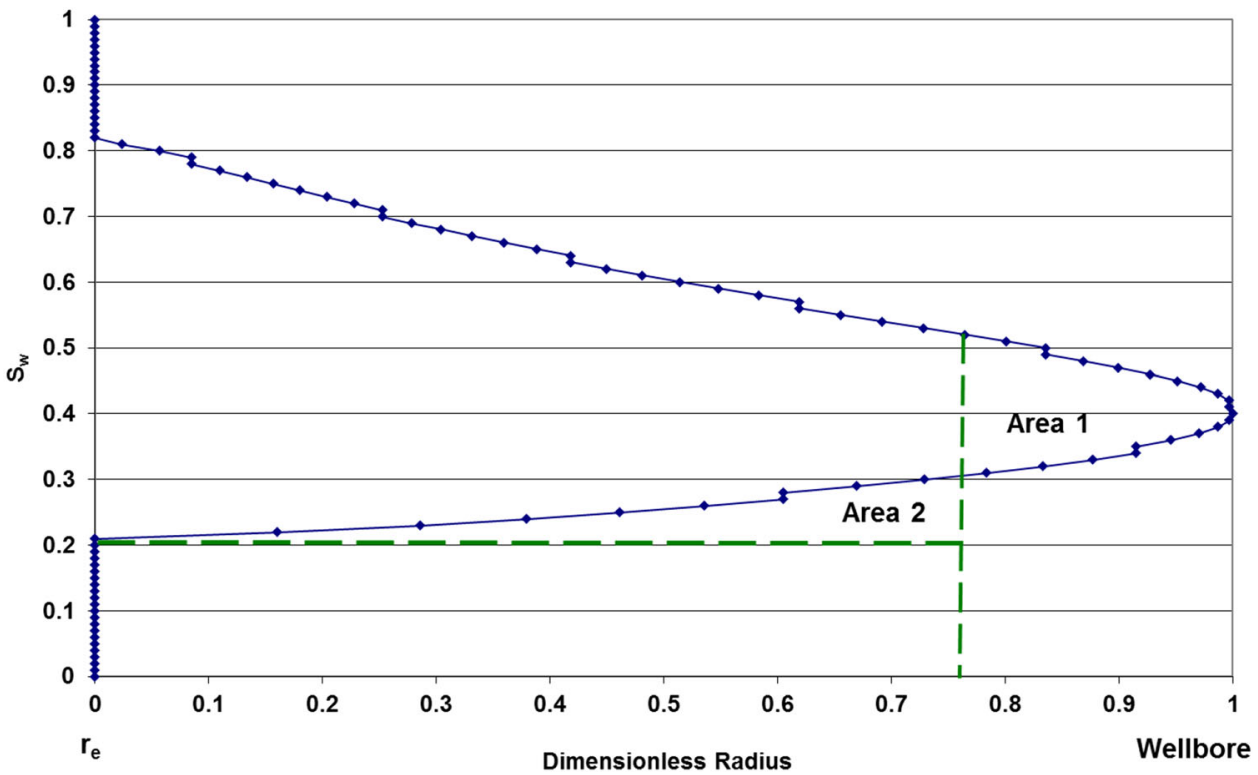

It should be noted that capillary pressure decreases as radius increases in this case. Therefore, $\frac{\partial P_{\mathrm{c}}}{\partial r}$ is negative. Comparing Eq. (12) with the fractional flow of linear displacement, we found that they are different. In linear displacement, the water saturation is calculated by (Buckley and Leverett 1942)

$f_{\mathrm{w}}=\frac{1-\frac{A k k_{\mathrm{ro}}}{q_{\mathrm{t}} \mu_{\mathrm{o}}} \frac{\partial P_{\mathrm{c}}}{\partial x}}{1+\frac{k_{\mathrm{r}} \mu_{\mathrm{w}}}{k_{\mathrm{rw}} \mu_{\mathrm{o}}}}$.

Therefore, linear displacement fractional flow equation cannot be used for radial displacement fractional flow. Equation (12) is the correct equation we should use in the radial system. If capillary pressure is negligible, Eq. (12) collapses into

$f_{\mathrm{w}}=\frac{1}{1+\frac{k_{\mathrm{ro}} \mu_{\mathrm{w}}}{k_{\mathrm{rw}} \mu_{\mathrm{o}}}}$.

Now, we derive the continuity equation of radial displacement. Considering the water displacing oil situation, material balance equation provides that the mass change in a control volume for a time period can be shown as Fig. 3. Since the flow direction is from reservoir outer boundary to the wellbore, for convenience, we define the reservoir boundary as the start point, where $r=0$, and the wellbore as the end point where $r=r_{\mathrm{e}}$. Therefore, in the dimensionless analysis, dimensionless radius can be defined as, $r_{\mathrm{D}}=r / r_{\mathrm{e}}$, the start point at the reservoir outer boundary will have $r_{\mathrm{D}}=0$, and the end point at the wellbore will have $r_{\mathrm{D}}=1$. Material balance gives us

$$
\begin{aligned}
& {\left[\left(q_{\mathrm{w}} \rho_{\mathrm{w}}\right)_{r}-\left(q_{\mathrm{w}} \rho_{\mathrm{w}}\right)_{r+\Delta r}\right] \Delta t=\pi h\left\{\left(r_{\mathrm{e}}-r\right)^{2}\right.} \\
& \left.\quad-\left[r_{\mathrm{e}}-(r+\Delta r)\right]^{2}\right\} \phi\left[\left(S_{\mathrm{w}} \rho_{\mathrm{w}}\right)^{\mathrm{t}+\Delta t}-\left(S_{\mathrm{w}} \rho_{\mathrm{w}}\right)^{\mathrm{t}}\right]
\end{aligned}
$$

where $S_{\mathrm{w}}$ is the water saturation, $\rho_{\mathrm{w}}$ is the water density, $\Delta t$ is the time period, $t$ is the time, $\Delta r$ is the radius incremental, $r$ is the radius from reservoir outer boundary to wellbore, $r_{\mathrm{e}}$ is the distance between reservoir outer boundary to wellbore, and $\phi$ is the porosity.

Simplifying Eq. (14), we have

$$
\begin{gathered}
{\left[\left(q_{\mathrm{w}} \rho_{\mathrm{w}}\right)_{r}-\left(q_{\mathrm{w}} \rho_{\mathrm{w}}\right)_{r+\Delta r}\right] \Delta t=\pi h\left[2 r_{\mathrm{e}} \Delta r-2 r \Delta r\right.} \\
\left.-(\Delta r)^{2}\right] \phi\left[\left(S_{\mathrm{w}} \rho_{\mathrm{w}}\right)^{\mathrm{t}+\Delta t}-\left(S_{\mathrm{w}} \rho_{\mathrm{w}}\right)^{\mathrm{t}}\right] .
\end{gathered}
$$

As $\Delta r \rightarrow 0$ and $\Delta t \rightarrow 0$, we have

$2 r_{\mathrm{e}} \Delta r-2 r \Delta r-(\Delta r)^{2} \approx 2 r_{\mathrm{e}} \Delta r-2 r \Delta r$.

Equation (15) becomes partial differential equation

$-\frac{\partial\left(q_{\mathrm{w}} \rho_{\mathrm{w}}\right)}{\partial r}=\left(2 r_{\mathrm{e}}-2 r\right) \pi h \phi \frac{\partial\left(S_{\mathrm{w}} \rho_{\mathrm{w}}\right)}{\partial t}$.

Assuming constant density ("Appendix A" shows the derivation of governing equation including the change of fluid density), we have

$-\frac{\partial q_{\mathrm{w}}}{\partial r}=\left(2 r_{\mathrm{e}}-2 r\right) \pi h \phi \frac{\partial S_{\mathrm{w}}}{\partial t}$.

Substituting Eq. (9) into (18) gives

$-\frac{\partial\left(f_{\mathrm{w}} q_{\mathrm{t}}\right)}{\partial r}=\left(2 r_{\mathrm{e}}-2 r\right) \pi h \phi \frac{\partial S_{\mathrm{w}}}{\partial t}$.

If the water encroachment rate is constant, we have a constant total liquid rate. Equation (19) can be simplified to 
Fig. 5 The correct plot of water saturation versus dimensionless radius
$S_{w}$ vs. Dimensionless Radius

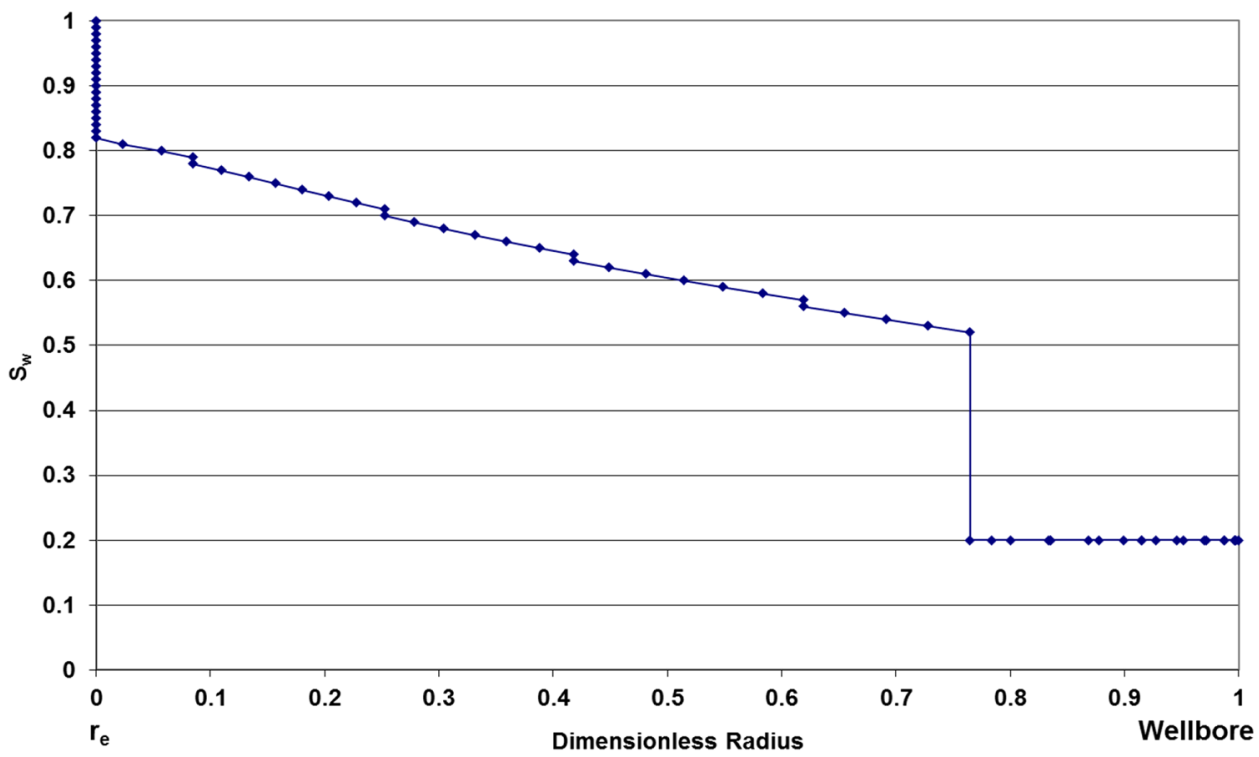

$-\frac{\partial f_{\mathrm{w}}}{\partial r}=\frac{\left(2 r_{\mathrm{e}}-2 r\right) \pi h \phi}{q_{\mathrm{t}}} \frac{\partial S_{\mathrm{w}}}{\partial t}$

Since water fraction is function of water saturation, $f_{\mathrm{w}}\left(S_{\mathrm{W}}\right)$

applying chain rule to partial differential equation results in

$-\frac{\mathrm{d} f_{\mathrm{w}}}{\mathrm{d} S_{\mathrm{w}}} \frac{\partial S_{\mathrm{w}}}{\partial r}=\frac{\left(2 r_{\mathrm{e}}-2 r\right) \pi h \phi}{q_{\mathrm{t}}} \frac{\partial S_{\mathrm{w}}}{\partial t}$.

At the first look Eq. (21) is similar to the Buckley-Leverett equation for linear displacement, we should notice that the term on the right-hand side before partial derivative is not constant.

Observing that water saturation is function of time, $t$, and position, $r$, we can express

$\mathrm{d} S_{\mathrm{w}}=\frac{\partial S_{\mathrm{w}}}{\partial t} \mathrm{~d} t+\frac{\partial S_{\mathrm{w}}}{\partial r} \mathrm{~d} r$

The fact that at the displacement front the water saturation is constant provides us a boundary condition.

Table 1 The input data for water displacing oil in a radial system

\begin{tabular}{ll}
\hline Injection rate (BWPD) & 50,000 \\
Radius (ft) & 5000 \\
Reservoir thickness (ft) & 50 \\
Initial oil saturation (fraction) & 0.8 \\
Irreducible oil saturation (fraction) & 0.2 \\
Oil viscosity (cp) & 0.93 \\
Water viscosity (cp) & 0.32 \\
Porosity (fraction) & 0.2 \\
\hline
\end{tabular}

Table 2 The relative permeabilities and calculated parameters versus water saturation

\begin{tabular}{lrllcl}
\hline$S_{\mathrm{w}}(\%)$ & $S_{\mathrm{o}}(\%)$ & $K_{\mathrm{ro}}$ & $K_{\mathrm{rw}}$ & $f_{\mathrm{w}}(\%)$ & $\mathrm{d} f / \mathrm{d} S_{\mathrm{w}}$ \\
\hline 0.0 & 100.0 & 0.4800 & 0.0000 & 0.0 & \\
20.00 & 80.0 & 0.4800 & 0.0000 & 0.0 & - \\
21.16 & 78.8 & 0.4594 & 0.0002 & 0.1 & 0.101 \\
22.32 & 77.7 & 0.4393 & 0.0007 & 0.5 & 0.321 \\
23.48 & 76.5 & 0.4196 & 0.0017 & 1.1 & 0.565 \\
24.64 & 75.4 & 0.4005 & 0.0030 & 2.1 & 0.834 \\
25.80 & 74.2 & 0.3819 & 0.0047 & 3.4 & 1.123 \\
26.96 & 73.0 & 0.3638 & 0.0067 & 5.1 & 1.430 \\
28.12 & 71.9 & 0.3461 & 0.0091 & 7.1 & 1.749 \\
29.28 & 70.7 & 0.3290 & 0.0119 & 9.5 & 2.074 \\
30.43 & 69.6 & 0.3123 & 0.0151 & 12.3 & 2.396 \\
31.59 & 68.4 & 0.2961 & 0.0187 & 15.4 & 2.707 \\
32.75 & 67.2 & 0.2804 & 0.0226 & 18.9 & 2.997 \\
33.91 & 66.1 & 0.2651 & 0.0269 & 22.7 & 3.258 \\
35.07 & 64.9 & 0.2504 & 0.0316 & 26.7 & 3.481 \\
36.23 & 63.8 & 0.2361 & 0.0366 & 30.9 & 3.659 \\
37.39 & 62.6 & 0.2222 & 0.0420 & 35.3 & 3.788 \\
38.55 & 61.4 & 0.2088 & 0.0478 & 39.8 & 3.864 \\
39.71 & 60.3 & 0.1959 & 0.0540 & 44.3 & 3.888 \\
40.87 & 59.1 & 0.1835 & 0.0605 & 48.8 & 3.861 \\
42.03 & 58.0 & 0.1715 & 0.0674 & 53.2 & 3.787 \\
43.19 & 56.8 & 0.1599 & 0.0747 & 57.5 & 3.672 \\
44.35 & 55.7 & 0.1488 & 0.0823 & 61.5 & 3.523 \\
45.51 & 54.5 & 0.1381 & 0.0904 & 65.4 & 3.346 \\
46.67 & 53.3 & 0.1279 & 0.0988 & 69.1 & 3.148 \\
47.83 & 52.2 & 0.1181 & 0.1075 & 72.5 & 2.937 \\
48.99 & 51.0 & 0.1087 & 0.1167 & 75.6 & 2.719 \\
50.14 & 49.9 & 0.0998 & 0.1262 & 78.5 & 2.499 \\
\hline & & & & &
\end{tabular}


Table 2 continued

\begin{tabular}{|c|c|c|c|c|c|}
\hline$S_{\mathrm{w}}(\%)$ & $S_{\mathrm{o}}(\%)$ & $K_{\text {ro }}$ & $K_{\mathrm{rw}}$ & $f_{\mathrm{w}}(\%)$ & $\mathrm{d} f / \mathrm{d} S_{\mathrm{w}}$ \\
\hline 51.30 & 48.7 & 0.0913 & 0.1361 & 81.2 & 2.282 \\
\hline 52.46 & 47.5 & 0.0832 & 0.1464 & 83.6 & 2.071 \\
\hline 53.62 & 46.4 & 0.0755 & 0.1570 & 85.7 & 1.868 \\
\hline 54.78 & 45.2 & 0.0683 & 0.1680 & 87.7 & 1.677 \\
\hline 55.94 & 44.1 & 0.0614 & 0.1794 & 89.4 & 1.497 \\
\hline 57.10 & 42.9 & 0.0550 & 0.1912 & 91.0 & 1.331 \\
\hline 58.26 & 41.7 & 0.0489 & 0.2033 & 92.3 & 1.177 \\
\hline 59.42 & 40.6 & 0.0432 & 0.2158 & 93.5 & 1.036 \\
\hline 60.58 & 39.4 & 0.0379 & 0.2287 & 94.6 & 0.907 \\
\hline 61.74 & 38.3 & 0.0330 & 0.2420 & 95.5 & 0.791 \\
\hline 62.90 & 37.1 & 0.0285 & 0.2556 & 96.3 & 0.686 \\
\hline 64.06 & 35.9 & 0.0243 & 0.2696 & 97.0 & 0.591 \\
\hline 65.22 & 34.8 & 0.0205 & 0.2840 & 97.6 & 0.507 \\
\hline 66.38 & 33.6 & 0.0171 & 0.2987 & 98.1 & 0.431 \\
\hline 67.54 & 32.5 & 0.0140 & 0.3138 & 98.5 & 0.364 \\
\hline 68.70 & 31.3 & 0.0112 & 0.3293 & 98.8 & 0.304 \\
\hline 69.86 & 30.1 & 0.0088 & 0.3452 & 99.1 & 0.251 \\
\hline 71.01 & 29.0 & 0.0067 & 0.3615 & 99.4 & 0.205 \\
\hline 72.17 & 27.8 & 0.0049 & 0.3781 & 99.6 & 0.164 \\
\hline 73.33 & 26.7 & 0.0034 & 0.3951 & 99.7 & 0.128 \\
\hline 74.49 & 25.5 & 0.0022 & 0.4124 & 99.8 & 0.097 \\
\hline 75.65 & 24.3 & 0.0013 & 0.4302 & 99.9 & 0.070 \\
\hline 76.81 & 23.2 & 0.0007 & 0.4483 & 99.9 & 0.047 \\
\hline 77.97 & 22.0 & 0.0002 & 0.4668 & 100.0 & 0.028 \\
\hline 79.13 & 20.9 & 0.0000 & 0.4856 & 100.0 & 0.013 \\
\hline 80.29 & 19.7 & 0.0000 & 0.5000 & 100.0 & 0.002 \\
\hline 81.45 & 18.6 & 0.0000 & 0.5000 & 100.0 & - \\
\hline 82.61 & 17.4 & 0.0000 & 0.5000 & 100.0 & - \\
\hline 83.77 & 16.2 & 0.0000 & 0.5000 & 100.0 & - \\
\hline 84.93 & 15.1 & 0.0000 & 0.5000 & 100.0 & - \\
\hline 86.09 & 13.9 & 0.0000 & 0.5000 & 100.0 & - \\
\hline 87.25 & 12.8 & 0.0000 & 0.5000 & 100.0 & - \\
\hline 88.41 & 11.6 & 0.0000 & 0.5000 & 100.0 & - \\
\hline 89.57 & 10.4 & 0.0000 & 0.5000 & 100.0 & - \\
\hline 90.72 & 9.3 & 0.0000 & 0.5000 & 100.0 & - \\
\hline 91.88 & 8.1 & 0.0000 & 0.5000 & 100.0 & - \\
\hline 93.04 & 7.0 & 0.0000 & 0.5000 & 100.0 & - \\
\hline 94.20 & 5.8 & 0.0000 & 0.5000 & 100.0 & - \\
\hline 95.36 & 4.6 & 0.0000 & 0.5000 & 100.0 & - \\
\hline 96.52 & 3.5 & 0.0000 & 0.5000 & 100.0 & - \\
\hline 97.68 & 2.3 & 0.0000 & 0.5000 & 100.0 & - \\
\hline 98.84 & 1.2 & 0.0000 & 0.5000 & 100.0 & - \\
\hline 100.00 & 0.0 & 0.0000 & 0.5000 & 100.0 & - \\
\hline
\end{tabular}

$\mathrm{d} S_{\mathrm{w}}=\frac{\partial S_{\mathrm{w}}}{\partial t} \mathrm{~d} t+\frac{\partial S_{\mathrm{w}}}{\partial r} \mathrm{~d} r=0$

or
Table 3 Comparisons of locations of different water saturations at a waterflooding time for linear and radial systems

\begin{tabular}{lll}
\hline $\begin{array}{l}\text { Water } \\
\text { saturation }\end{array}$ & $\begin{array}{l}\text { Location of water } \\
\text { saturation in linear system } \\
(\mathrm{ft})\end{array}$ & $\begin{array}{l}\text { Location of water } \\
\text { saturation in radial system } \\
(\mathrm{ft})\end{array}$ \\
\hline 0.397 & 1389.7 & 751.3 \\
0.409 & 1380.0 & 745.6 \\
0.420 & 1353.7 & 730.2 \\
0.432 & 1312.6 & 706.2 \\
0.443 & 1259.2 & 675.2
\end{tabular}

$\begin{array}{lll}0.455 & 1195.9 & 638.7\end{array}$

$\begin{array}{lll}0.467 & 1125.4 & 598.5\end{array}$

$\begin{array}{lll}0.478 & 1050.0 & 555.9\end{array}$

$\begin{array}{lll}0.490 & 972.1 & 512.3\end{array}$

$\begin{array}{lll}0.501 & 893.4 & 468.7\end{array}$

$\begin{array}{lll}0.513 & 815.7 & 426.0\end{array}$

$\begin{array}{lll}0.525 & 740.2 & 384.9\end{array}$

$\begin{array}{lll}0.536 & 667.9 & 345.9\end{array}$

$\begin{array}{lll}0.548 & 599.4 & 309.3\end{array}$

$\begin{array}{lll}0.559 & 535.2 & 275.2\end{array}$

$\begin{array}{lll}0.571 & 475.6 & 243.8\end{array}$

$\begin{array}{lll}0.583 & 420.6 & 214.9\end{array}$

$\begin{array}{lll}0.594 & 370.3 & 188.7\end{array}$

$\begin{array}{lll}0.606 & 324.4 & 164.9\end{array}$

$\begin{array}{lll}0.617 & 282.8 & 143.4\end{array}$

$\begin{array}{lll}0.629 & 245.2 & 124.1\end{array}$

$\begin{array}{lll}0.641 & 211.4 & 106.8\end{array}$

$\begin{array}{lll}0.652 & 181.1 & 91.4\end{array}$

$\begin{array}{lll}0.664 & 154.1 & 77.7\end{array}$

$\begin{array}{lll}0.675 & 130.0 & 65.4\end{array}$

$\begin{array}{lll}0.687 & 108.7 & 54.6\end{array}$

$\begin{array}{lll}0.699 & 89.8 & 45.1\end{array}$

$\begin{array}{lll}0.710 & 73.1 & 36.7\end{array}$

$\begin{array}{lll}0.722 & 58.5 & 29.3\end{array}$

$\begin{array}{lll}0.733 & 45.7 & 22.9\end{array}$

$\begin{array}{lll}0.745 & 34.6 & 17.3\end{array}$

$\begin{array}{lll}0.757 & 25.1 & 12.5\end{array}$

$\begin{array}{lll}0.768 & 16.9 & 8.5\end{array}$

$\begin{array}{lll}0.780 & 10.1 & 5.1\end{array}$

$\begin{array}{lll}0.791 & 4.6 & 2.3\end{array}$

$\begin{array}{lll}0.803 & 0.8 & 0.4\end{array}$

$\begin{array}{lll}0.814 & 0.0 & 0.0\end{array}$

$\frac{\partial S_{\mathrm{w}}}{\partial r}=-\frac{\partial S_{\mathrm{w}}}{\partial t} \frac{\mathrm{d} t}{\mathrm{~d} r}$.

Substituting Eq. (23) into (21) yields

$-\frac{\mathrm{d} f_{\mathrm{w}}}{\mathrm{d} S_{\mathrm{w}}}\left(-\frac{\partial S_{\mathrm{w}}}{\partial t} \frac{\mathrm{d} t}{\mathrm{~d} r}\right)=\frac{\left(2 r_{\mathrm{e}}-2 r\right) \pi h \phi}{q_{\mathrm{t}}} \frac{\partial S_{\mathrm{w}}}{\partial t}$

or 
Fig. 6 Comparisons of locations of different water saturations at a waterflooding time for linear and radial systems
Water Saturation vs. Water Saturation Location at a Waterflooding Time

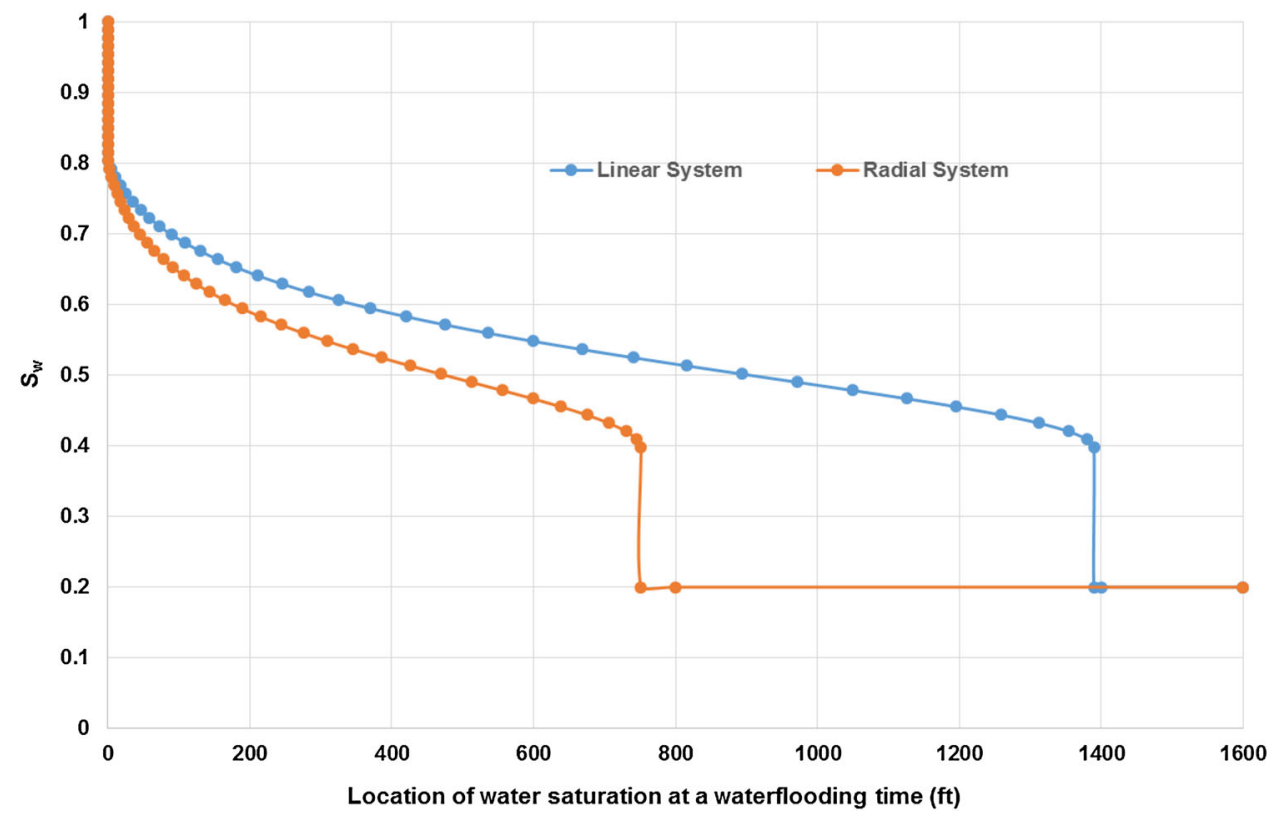

$\frac{\mathrm{d} f_{\mathrm{w}}}{\mathrm{d} S_{\mathrm{w}}} \mathrm{d} t=\frac{\left(2 r_{\mathrm{e}}-2 r\right) \pi h \phi}{q_{\mathrm{t}}} \mathrm{d} r$.

Integrating Eq. (24) yields an equation for displacement front position, $r_{\mathrm{f}}$.

$\frac{\pi h \phi}{q_{\mathrm{t}}}\left(2 r_{\mathrm{e}} r_{\mathrm{f}}-r_{\mathrm{f}}^{2}\right)=\left(\frac{\mathrm{d} f_{\mathrm{w}}}{\mathrm{d} S_{\mathrm{w}}}\right)_{\mathrm{f}} t$

or

$r_{\mathrm{f}}^{2}-2 r_{\mathrm{e}} r_{\mathrm{f}}+\frac{t q_{\mathrm{t}}}{\pi h \phi}\left(\frac{\mathrm{d} f_{\mathrm{w}}}{\mathrm{d} S_{\mathrm{w}}}\right)_{\mathrm{f}}=0$

where $r_{\mathrm{f}}$ is the displacement front position in radial system.

There are two solutions to Eq. (25), which are

$r_{\mathrm{f}}=r_{\mathrm{e}} \pm \sqrt{r_{\mathrm{e}}^{2}-\frac{t q_{\mathrm{t}}}{\pi h \phi}\left(\frac{\mathrm{d} f_{\mathrm{w}}}{\mathrm{d} S_{\mathrm{w}}}\right)_{\mathrm{f}}}$.

Obviously only one solution is correct to match with the physical phenomenon. Considering at the beginning of the displacement as $t \rightarrow 0$, we have $r_{\mathrm{f}} \rightarrow 0$; therefore, we can eliminate the solution

$r_{\mathrm{f}}=r_{\mathrm{e}}+\sqrt{r_{\mathrm{e}}^{2}-\frac{t q_{\mathrm{t}}}{\pi h \phi}\left(\frac{\mathrm{d} f_{\mathrm{w}}}{\mathrm{d} S_{\mathrm{w}}}\right)_{\mathrm{f}}}$.

Therefore, the correct solution is

$r_{\mathrm{f}}=r_{\mathrm{e}}-\sqrt{r_{\mathrm{e}}^{2}-\frac{t q_{\mathrm{t}}}{\pi h \phi}\left(\frac{\mathrm{d} f_{\mathrm{w}}}{\mathrm{d} S_{\mathrm{w}}}\right)_{\mathrm{f}}}$.

The distance between the wellbore and water front will be calculated by
Table 4 Comparisons of water front location versus waterflooding time for linear and radial systems

\begin{tabular}{lcc}
\hline $\begin{array}{l}\text { Waterflooding time } \\
\text { (days) }\end{array}$ & $\begin{array}{l}\text { Location of water front } \\
\text { in linear system }(\mathrm{ft})\end{array}$ & $\begin{array}{l}\text { Location of water front } \\
\text { in radial system }(\mathrm{ft})\end{array}$ \\
\hline 0.1 & 0.7 & 0.3 \\
1 & 6.9 & 3.5 \\
20 & 139.0 & 70.0 \\
30 & 208.5 & 105.3 \\
50 & 347.4 & 176.8 \\
100 & 694.8 & 360.4 \\
150 & 1042.3 & 551.5 \\
200 & 1389.7 & 751.3 \\
250 & 1737.1 & 960.9 \\
300 & 2084.5 & 1182.0 \\
350 & 2431.9 & 1416.7 \\
400 & 2779.3 & 1667.8 \\
450 & 3126.8 & 1939.6 \\
500 & 3474.2 & 2237.9 \\
550 & 3821.6 & 2572.7 \\
600 & 4169.0 & 2961.6 \\
650 & 4516.4 & 3445.1 \\
700 & 4863.8 & 4174.9 \\
710 & 4933.3 & 4422.6 \\
719.6 & 5000.0 & 5000.0 \\
\hline
\end{tabular}

$r_{\text {well-to-waterfront }}=r_{\mathrm{e}}-r_{\mathrm{f}}=\sqrt{r_{\mathrm{e}}^{2}-\frac{t q_{\mathrm{t}}}{\pi h \phi}\left(\frac{\mathrm{d} f_{\mathrm{w}}}{\mathrm{d} S_{\mathrm{w}}}\right)_{\mathrm{f}}}$.

Again, if we compare Eq. (28) with the linear displacement, we found that it is distinct from the 
Fig. 7 Comparisons of water front location versus waterflooding time for linear and radial systems

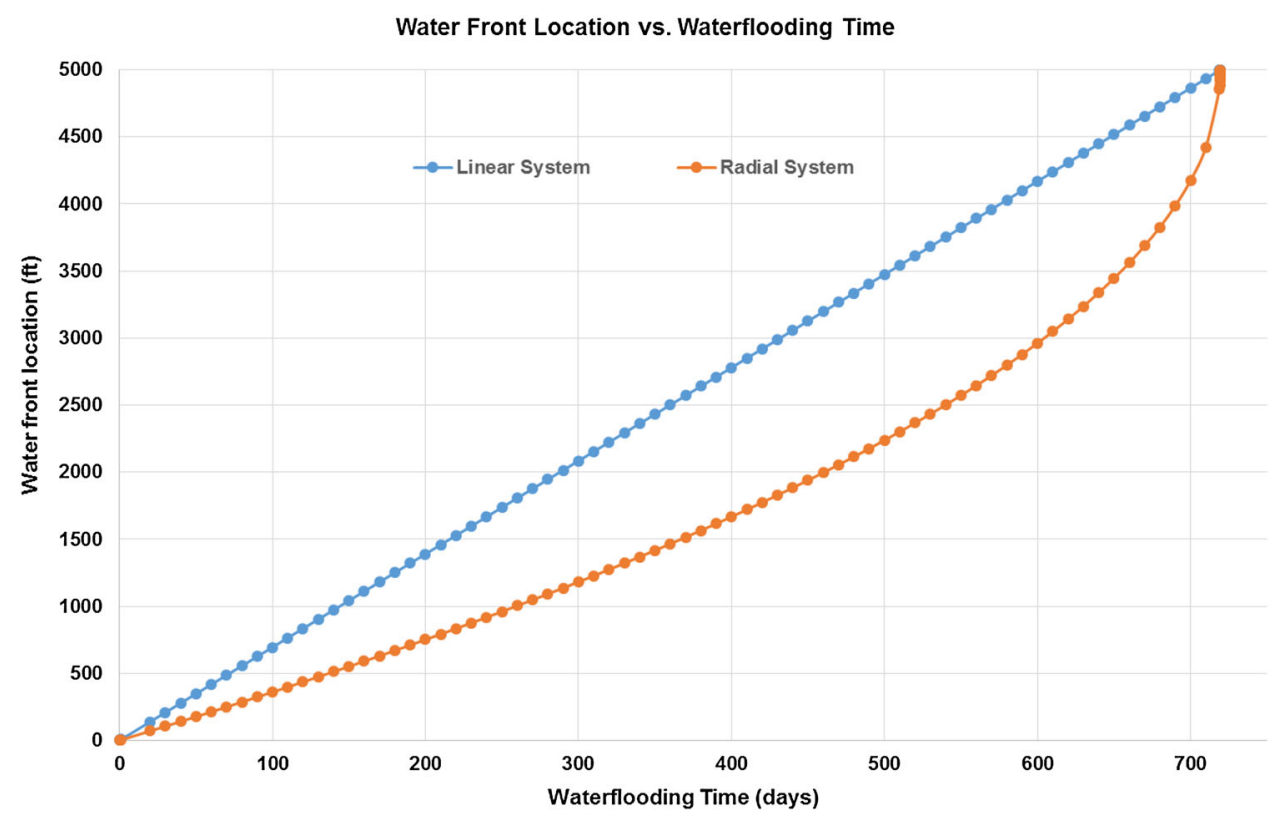

displacement front of linear displacement system, which is

$x_{\mathrm{f}}=\frac{t q_{\mathrm{t}}}{A \phi}\left(\frac{\mathrm{d} f_{\mathrm{w}}}{\mathrm{d} S_{\mathrm{w}}}\right)_{\mathrm{f}}$

where $x_{\mathrm{f}}$ is the displacement front position in the linear system.

Therefore, linear displacement fractional flow equation cannot be used to locate the position of displacement front in a radial displacement system. Equation (28) is the correct equation we should use in the radial system.

For any water saturation, $S_{\mathrm{w}}$, the position can be calculated by

$r_{S_{\mathrm{w}}}=r_{\mathrm{e}}-\sqrt{r_{\mathrm{e}}^{2}-\frac{t q_{\mathrm{t}}}{\pi h \phi}\left(\frac{\mathrm{d} f_{\mathrm{w}}}{\mathrm{d} S_{\mathrm{w}}}\right)_{S_{\mathrm{w}}}}$

where $r_{S_{\mathrm{w}}}$ is the position of any water saturation in radial system.

The plot of water saturation versus dimensionless radius based on Eq. (31) indicates that the plot needs to be modified to match with the physical model. Here, dimensionless radius is defined as:

$r_{\mathrm{D}}=\frac{r}{r_{\mathrm{e}}}$.

Figure 4 shows the plot of water saturation versus dimensionless radius based on Eq. (31).

Figure 4 gives two saturation values for the same position. Physically, it is impossible. The modification to Fig. 4 to get the correct water saturation distribution can be accomplished by determining displacement front position. To determine the displacement front location, one can define a saturation discontinuity (or displacement front) at $r_{\mathrm{f}}$ and balancing of the areas ahead of the front (Area 1) and below (Area 2) the saturation curve shown in Fig. 4. Then, the water saturation ahead of the displacement front should be the initial water saturation. The correct water saturation distribution is shown in Fig. 5.

\section{Case study}

A case study was conducted to illustrate the analysis of radial water displacing oil procedure. The input data are shown in Table 1. Table 2 shows the relative permeabilities and calculated parameters versus water saturation.

The plot of water saturation versus dimensionless radius is shown in Fig. 5. If linear displacement equation is used, the position of the displacement front will be quite different. The processes of water displacing oil in linear and radial systems are compared to illustrate the difference. All inputs are the same in the comparison. The comparisons of locations of different water saturations at a waterflooding time for linear and radial systems are shown in Table 3 and Fig. 6. The comparisons of water front location at different waterflooding times for linear and radial systems are shown in Table 4 and Fig. 7. The differences in these tables and figures indicate that Buckley-Leverett linear displacement is not appropriate for peripheral waterflood reservoirs.

\section{Conclusions}

The following conclusions can be drawn upon this study. 
The performance of radial water displacing oil system is different from that of linear water displacing oil system.

If consider the effect of capillary pressure, equations used to calculate water fraction are different between linear and radial displacement systems. Linear displacement system equation cannot be used for the radial displacement system. Equation (12) should be used to estimate the water fraction.

Equations used to calculate the position of any water saturation are different between linear and radial displacement systems. Linear displacement system equation cannot be used for the radial displacement system. Equation (31) should be used to estimate the position of any water saturation.

Acknowledgments This paper was firstly presented at the SPE Latin American and Caribbean Petroleum Engineering Conference held in Mexico City, Mexico, 16-18 April 2012. The authors thank Society of Petroleum Engineers (SPE) in allowing us to publish this paper with Journal of Petroleum Exploration and Production Technology.

Open Access This article is distributed under the terms of the Creative Commons Attribution 4.0 International License (http:// creativecommons.org/licenses/by/4.0/), which permits unrestricted use, distribution, and reproduction in any medium, provided you give appropriate credit to the original author(s) and the source, provide a link to the Creative Commons license, and indicate if changes were made.

\section{Appendix A}

Expanding Eq. (17) we have

$-\rho_{\mathrm{w}} \frac{\partial q_{\mathrm{w}}}{\partial r}-q_{\mathrm{w}} \frac{\partial \rho_{\mathrm{w}}}{\partial r}=\left(2 r_{\mathrm{e}}-2 r\right) \pi h \phi\left[\rho_{\mathrm{w}} \frac{\partial S_{\mathrm{w}}}{\partial t}+S_{\mathrm{w}} \frac{\partial \rho_{\mathrm{w}}}{\partial t}\right]$.

Applying chain rule we obtain

$$
\begin{gathered}
-\rho_{\mathrm{w}} \frac{\partial q_{\mathrm{w}}}{\partial r}-q_{\mathrm{w}} \frac{\partial \rho_{\mathrm{w}}}{\partial p_{\mathrm{w}}} \frac{\partial p_{\mathrm{w}}}{\partial r}=\left(2 r_{\mathrm{e}}-2 r\right) \\
\pi h \phi\left[\rho_{\mathrm{w}} \frac{\partial S_{\mathrm{w}}}{\partial t}+S_{\mathrm{w}} \frac{\partial \rho_{\mathrm{w}}}{\partial p_{\mathrm{w}}} \frac{\partial p_{\mathrm{w}}}{\partial t}\right] .
\end{gathered}
$$

Now introducing the concept of water compressibility, which is defined as

$c_{\mathrm{w}}=-\frac{1}{V}\left(\frac{\partial V}{\partial p}\right)_{T}=\frac{1}{\rho_{\mathrm{w}}}\left(\frac{\partial \rho_{\mathrm{w}}}{\partial p}\right)$.

Substituting Eq. (35) into (34) gives

$$
\begin{gathered}
-\rho_{\mathrm{w}} \frac{\partial q_{\mathrm{w}}}{\partial r}-q_{\mathrm{w}} c_{\mathrm{w}} \rho_{\mathrm{w}} \frac{\partial p_{\mathrm{w}}}{\partial r}=\left(2 r_{\mathrm{e}}-2 r\right) \\
\pi h \phi\left[\rho_{\mathrm{w}} \frac{\partial S_{\mathrm{w}}}{\partial t}+S_{\mathrm{w}} c_{\mathrm{w}} \rho_{\mathrm{w}} \frac{\partial p_{\mathrm{w}}}{\partial t}\right] .
\end{gathered}
$$

Substituting Eq. (9) into (36) yields

$$
\begin{aligned}
& -\rho_{\mathrm{w}} \frac{\partial\left(f_{\mathrm{w}} q_{\mathrm{t}}\right)}{\partial r}-f_{\mathrm{w}} q_{\mathrm{t}} c_{\mathrm{w}} \rho_{\mathrm{w}} \frac{\partial p_{\mathrm{w}}}{\partial r}=\left(2 r_{\mathrm{e}}-2 r\right) \\
& \pi h \phi\left[\rho_{\mathrm{w}} \frac{\partial S_{\mathrm{w}}}{\partial t}+S_{\mathrm{w}} c_{\mathrm{w}} \rho_{\mathrm{w}} \frac{\partial p_{\mathrm{w}}}{\partial t}\right] .
\end{aligned}
$$

If the water encroachment rate is constant, we have a constant total liquid rate. Equation (37) can be simplified to

$-\left[\frac{\partial f_{\mathrm{w}}}{\partial r}+f_{\mathrm{w}} c_{\mathrm{w}} \frac{\partial p_{\mathrm{w}}}{\partial r}\right]=\frac{\left(2 r_{\mathrm{e}}-2 r\right) \pi h \phi}{q_{\mathrm{t}}}\left[\frac{\partial S_{\mathrm{w}}}{\partial t}+S_{\mathrm{w}} c_{\mathrm{w}} \frac{\partial p_{\mathrm{w}}}{\partial t}\right]$.

Expressing the pressure in terms of radius we have

$p_{\mathrm{w}}=\frac{f_{\mathrm{w}} q_{\mathrm{t}} \mu_{\mathrm{w}}}{2 \pi k k_{\mathrm{rw}} h} \ln \frac{r}{r_{\mathrm{w}}}+p_{\mathrm{wf}}$.

Taking the derivative of both sides of Eq. (39) with respect to $r$ gives

$\frac{\partial p_{\mathrm{w}}}{\partial r}=\frac{f_{\mathrm{w}} q_{\mathrm{t}} \mu_{\mathrm{w}}}{2 \pi k k_{\mathrm{rw}} h} \frac{1}{r}$.

For the same location (or radius in this case), water pressure change with respect to time can be approximated by capillary pressure change with respect to time,

$\frac{\partial p_{\mathrm{w}}}{\partial t}=-\frac{\partial P_{\mathrm{c}}}{\partial t}$.

According to Brooks and Corey (1964) capillary pressure model capillary pressure can be expressed as

$P_{\mathrm{c}}=P_{\mathrm{d}}\left(\frac{S_{\mathrm{w}}-S_{\mathrm{wi}}}{1-S_{\mathrm{wi}}}\right)^{\frac{-1}{\lambda}}$

where, $S_{\mathrm{wi}}=$ the irreducible water saturation, $P_{\mathrm{d}}=$ the threshold pressure, $\lambda=$ rock property parameter related to the distribution of pore sizes.

Brooks and Corey related the parameter $\lambda$ to the distribution of pore sizes. For narrow distributions, $\lambda$ is $>2$; for wide distributions, $\lambda$ is $<2$.

Substituting Eq. (42) into (43) we have

$\frac{\partial p_{\mathrm{w}}}{\partial t}=\frac{P_{\mathrm{d}}}{\lambda\left(1-S_{\mathrm{wi}}\right)}\left(\frac{S_{\mathrm{w}}-S_{\mathrm{wi}}}{1-S_{\mathrm{wi}}}\right)^{\frac{-1}{\lambda}-1} \frac{\partial S_{\mathrm{w}}}{\partial t}$.

Substituting Eqs. (40) and (43) into (38) yields

$$
\begin{aligned}
& \frac{\partial f_{\mathrm{w}}}{\partial r}+f_{\mathrm{w}} c_{\mathrm{w}}\left(\frac{f_{\mathrm{w}} q_{\mathrm{t}} \mu_{\mathrm{w}}}{2 \pi k k_{\mathrm{rw}} h} \frac{1}{r}\right)=\frac{\left(2 r-2 r_{\mathrm{e}}\right) \pi h \phi}{q_{\mathrm{t}}} \\
& {\left[1+S_{\mathrm{w}} c_{\mathrm{w}} \frac{P_{\mathrm{d}}}{\lambda\left(1-S_{\mathrm{wi}}\right)}\left(\frac{S_{\mathrm{w}}-S_{\mathrm{wi}}}{1-S_{\mathrm{wi}}}\right)^{\frac{-1}{\lambda}-1}\right] \frac{\partial S_{\mathrm{w}}}{\partial t} .}
\end{aligned}
$$

Equation (44) can be solved numerically to obtain the location of any water saturation at any waterflooding time. 
If the capillary pressure is small and can be ignored, Eq. (44) becomes

$\frac{\partial f_{\mathrm{w}}}{\partial r}+f_{\mathrm{w}} c_{\mathrm{w}}\left(\frac{f_{\mathrm{w}} q_{\mathrm{t}} \mu_{\mathrm{w}}}{2 \pi k k_{\mathrm{rw}} h} \frac{1}{r}\right)=\frac{\left(2 r-2 r_{\mathrm{e}}\right) \pi h \phi}{q_{\mathrm{t}}} \frac{\partial S_{\mathrm{w}}}{\partial t}$.

\section{References}

Brooks RH, Corey AT (1964) Hydraulic properties of porous media. Hydrology Paper No. 3, Colorado State University, Fort Collins, Colorado, pp 22-27

Buckley SE, Leverett MC (1942) Mechanism of fluid displacement in sands. Trans AIME 146:107
Dykstra H, Parsons RL (1950) The prediction of oil recovery by waterflooding. In: American Petroleum Institution (ed) Secondary recovery of oil in the United States, 2nd edn. API, pp 160-174

El-Khatib NA (1999) Waterflooding performance of communicating stratified reservoirs with log-normal permeability distribution. SPEREE 2:542-549

Hearn CL (1971) Simulation of stratified waterflooding by pseudo relative permeability curves. J Pet Technol 23(7):805-813

Stiles WE (1949) Use of permeability distribution in water-flood calculations. Trans AIME 186:9-13

Welge HJ (1952) A simplified method for computing oil recovery by gas or water drive. Trans AIME 195:91-98 